\title{
APPROACHES TO DESIGNING OF LOGISTICS SYSTEMS IN TERMS OF RELATIONSHIP OF KNOWLEDGE LEVEL AND SOLUTION EFFICIENCY AND THEIR APPLICATION IN METALLURGY
}

\author{
Dušan MALINDŽÁK, Ján SPIŠÁK, Olga VÉGSOOVÁ \\ Technical University of Košice, Košice, Slovak Republic, EU, \\ dusan.malindzak@tuke.sk, jan.spisak@tuke.sk, olga.vegsoova@tuke.sk
}

https://doi.org/10.37904/metal.2019.786

\begin{abstract}
The process of designing logistics systems in metallurgy in many cases depends on solution time, resources used and complexity of the problem - the efficiency of the solution. From this point of view, it is possible to divide the design methods into 3 levels, from the lowest, naive level (situational - ad hoc decision) and analogy, through application of models/analytical heuristic and simulation models to the highest level, complex-system approach, scientific level. The article describes the suitability of individual approaches, models, knowledge, principles, rules and their application for different paradigms of logistic systems (case study, reengineering, system approach) in metallurgy.
\end{abstract}

Keywords: Designing, logistics system, levels of knowledge, metallurgy

\section{INTRODUCTION}

The aim of the paper is to show diversity of tools, methods, approaches used in various paradigms of designing logistic and technological systems in metallurgy. A very important part of the metallurgical industry is logistics - organizing, planning, managing and performing flows starting with development and purchasing, ending with production and distribution according to the order of the final customer $[1,2]$.

Logistics system design is the process of creating a logistics system project. It has two sides [2]:

1) Creative - How to do it? - Know-how, principles, rules, methods, procedures, methodologies.

2) Project - Make a project that is the basis for implementing a logistics system.

Basic characteristics of the logistic system design:

- design processes and creation process of the designers are carried out in conditions of limited information - incorrectly structured problems,

- alternatives, possibilities and results are not known in advance and that is why they are supposed to be found within the process of design,

- in most cases, the optimal solution is not expected, an acceptable and suitable solution is searched for, - $\quad$ most of the properly structured problems (mathematically described) do not have an optimal solution.

With the knowledge development, two spheres of natural and technical sciences have been established [2]. Natural science is more oriented towards obtaining new knowledge, defining new principles and rules. Technical, engineering science is oriented towards the application of this newly discovered knowledge for designing purposes. The design process is similar, irrespective of the subject, concept or design method. The design process shows the aspects of:

1) cycle - iteration,

2) cognition - novelty,

3) evolution (revolution) - development. 


\section{PARADIGMS OF DESIGN AND APPLICATION OF KNOWLEDGE LEVEL}

The extent and quality of the changes needed to solve a defined problem and objectives apparent choice paradigm for designing the logistics and technological systems. Paradigm is a framework, approach, methodology, guidance for problem solving. Within one paradigm, multiple methods can be applied, applying different levels of knowledge, such as:

1) case study,

2) reengineering and redesign,

3) system approach.

We choose the case study, if we are talking about the solution of a separate case, which doesn't have a definitive impact on the other logistics activities and significantly doesn't interferes the whole logistics system. E.g., if a problem is to find an optimal distribution path of goods ordered for customers for summer season, this is a one-shot solution prepared and realized fast.

Reengineering method is applied when we are talking about radical change of the logistics system, which interfere with several functional areas of the company. E.g. if it is needed:

- To find an optimal composition of product selection and find a sequence of its production.

- It is needed to decide whether micro MRP wouldn't be better for the system than the pull system.

- $\quad$ Flexibility of order observation is not sufficient; it is necessary to decide about the structure of planning system.

- Current criteria of order accumulation don't reflect the new situation in the energy prices, etc.

But we are still talking about a large main system change.

System approach - Analysis - Synthesis - Evaluation (A-S-E) is chosen in case of a new proposal for new logistics system for an enlarged company, for an area which was not taken into consideration so far. There is enough time and financial resources for such a change. E.g., a company enlarges its production with some new range of goods for a new market. It is important to design logistics system for a new division, new procurement system, system of production processes management, distribution system, etc. and connect such a system to the existing logistics system of the company. This is a change in the structure of the logistics system, systemic change.

The selection of the paradigm will influence the whole further design process and project preparation. The choice of the design paradigm according to the level of knowledge of the problem defined on the basis of the results of the flash analysis of the problem, respectively, after the logistics-technological audit performed usually corresponds to the following scale:

1) Rating level $81-100 \%$ - kaizen current system, case study.

2) Rating level $50-80 \%$ - reengineering or redesigning an existing system.

3) Evaluation level below $50 \%$ - A-S-E model approach resulting in a new logistics system.

In each paradigm, some of the processes might be realized differently. While gathering of information, selection of knowledge, research, generation of alternatives is dominant in model approach (scientific approach), in case studies is this phase simplified into search for solution with similar conditions and situations. Focus is given to the evaluation of the alternatives and suitability of the solution (pragmatic approach). In simulation, the focus is on generation of solutions and evaluation of the simulation (functional model). Heuristic approach uses solution methods applied by a human and definition of rules and limitations, which such a design - solution should fulfil $[1,2,3,4,5]$. 


\subsection{Case study}

Case study focuses on research and projection of a concrete case and its pragmatic solution provision, not theoretical solution. That is why it is possible to consider this approach for an empirical approach to a synthesis of a logistics system. Case study is more a method of application research than a basic research. One unique solution of particular case creates the result of this approach. The result is a concrete project of solution application, not a theoretical knowledge, principle or method. Case study bases on analogy $[2,6]$. We are looking for a solution by comparing details (case, situation) of another solution for other similar case. If such a gauge is found, we use it and adjust it to the specific conditions of our case. Analogy in this case is a theoretical principle of case studies. There are two situations when cases are analogical $[2,7]$ :

- $\quad$ if they have the same structure,

- if they have same characteristics of their elements.

Compared to the heuristic approach, case study differs in the definition of rules on the analogy with one situation - etalon. Case study bases on a similar approach as "benchmarking". There is always a risk of stability and validity of such a solution due to conclusion making based on one or several cases. The results of such solution might be less trustworthy. Other risks evolve from the non-systematism of such solution, meaning it cannot be included into the system (e.g. company management - when problems from non- comprehension of relations and impacts on other functions and processes might occur). On the other side, based on the concluded volume of problem, it is possible to analyze it into the depth and find available and acceptable solution.

To apply the "case study" paradigm, knowledge is most necessary:

- $\quad$ elementary - primary decision making, deduction, abduction,

- $\quad$ analogy and search for a standard,

- benchmarking.

Case study belongs to "approximate methods" of projection. From the project type point of view, case study provides an innovative, respectively repetitive proposal for solution.

\subsection{Reengineering}

Reengineering is a design paradigm of all business processes - technological, logistics, economic processes. Then those processes are selected which with the smallest expenses bring the biggest profit (SWOT analysis features) and usually it is needed to pragmatically realize them (case study) in shortest time possible.

Second characteristic feature of reengineering is, that logistics system design is carried out in already existing company, which has "some logistic system". It is possible that all other possibilities for new solution have been used by sequential innovative tasks (kaizen, evolution approach) and it is needed to change some of the processes radically. But a radical change means a systemic change. It does not design a completely new system because a solution must be applied during operation and several times while critical stage of a company. That is why reengineering project is a radical innovative project.

Reengineering is one of the methods that ensures the competitiveness of a company and which solves the problem of attrition of possibilities for effectiveness and rationalization of micro-processes. Reengineering can be applied in 3 levels:

1) technological,

2) logistics,

3) economic.

Reengineering re-values the basis of individual processes, investigates their quantitative and qualitative features and at the same time focuses on validity of their execution in relation to global criterion. If particular 
process does not add any added value to the product, if it does not improve services oriented to customers $[1,2,3,4,5,8]$.

Reengineering is asking these questions: Why do we do what we do, does it have to be like that and whether we have to do it? It is not getting satisfied with improvements or partial changes of business activities but it thinks complexly. That way it differs from lasting process of improvement.

In reengineering, all currently operating processes are critically viewed, newly structured and re-build. It is determined how such process should look like so it satisfied requirements of the customers and the market and not considering the currently valid organizational structure. Processes, not the organizational units are in the middle of the attention. Reengineering does not focus on changes within individual parts but views the company as one big entity.

For reengineering application is needed knowledge:

- $\quad$ SWOT analysis for selection of processes and functions.

- Heuristics for modelling interface processes such as: annual planning, capacity and operational planning, production scheduling, distribution plans.

- $\quad$ Methods for analyzing and acquiring knowledge, rules from experts (thinking aloud, brainstorming) ...

- $\quad$ Simulation methods for verification of plans and designing processes as queuing systems.

- Analytical models, in particular operational analysis models.

- Knowledge of technological processes.

\subsection{System approach}

This approach (model approach) belongs to theoretical, scientific and normative approaches or strategies. We perceive a logistics system as a system of functions - tasks. That is why the focus will be given to material, information and financial flows, their logistics and realization. Model approach has gained its name based on three viewpoints [2,7]:

1) From global structure of design steps - meaning that we apply a model problem $\rightarrow$ goals $\rightarrow$ analysis $\rightarrow$ synthesis $\rightarrow$ realization (simulation) $\rightarrow$ evaluation; it uses the whole systemic projection technique.

2) From structure of management system - logistics systems are stochastic systems with big inertia and long response to managing intervention. That is why a forward's management system is applied (see Figure 1).

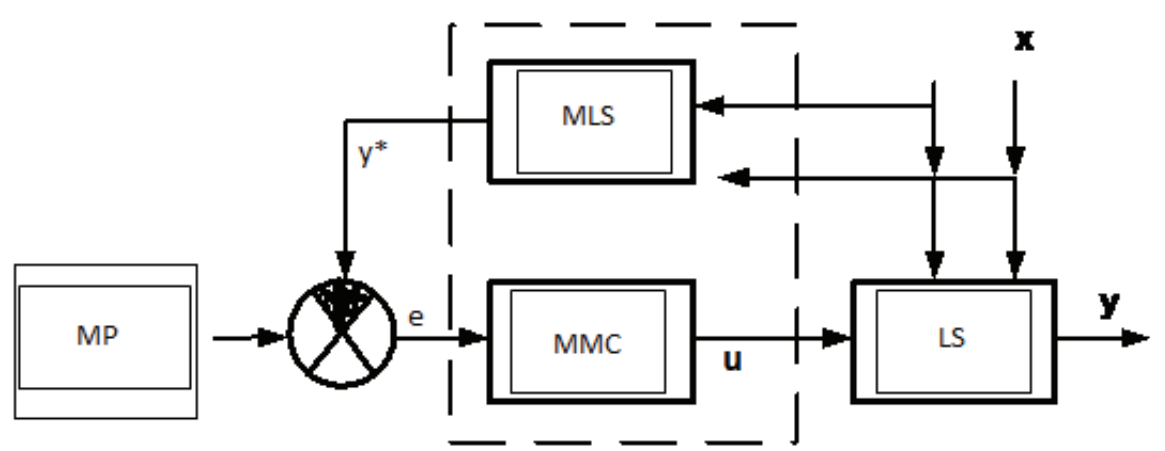

MLS - logistics system model, MP - models for planning, MMC - models for management and control, LS - logistics system, $x$ - vector of inputs, $y$ - vector of outputs, $y^{*}$ - vector of simulated outputs, $u$ vector of management decisions, $\mathrm{e}$ - vector of aviation.

Figure 1 Feed forward structure of logistics system

Model approach is applied in new system design or in case of a major change and reconstruction of the system. Due to these reasons, the synthesis of logistics system focuses on: 
- design of logistics system structure,

- design of processes,

- design of functions where inputs, output, outer relations are defined.

3) From inner view point - whole design bases on model creation (MLS, MP, MMC). The solution is based with the help of model, e.g. analytical, simulation, heuristic, statistical, information. The optimal or suitable solution is found on the model and that solution is then applied to the real system and apply the model in real management of logistics system (see Figure1).

For the paradigm of the system model is needed knowledge:

- $\quad$ system theory,

- $\quad$ system analysis methods,

- methodology of creating heuristic and simulation models,

- operational analysis models and their application,

and all that is needs for the previous paradigms.

\section{EXAMPLES OF APPLICATIONS OF INDIVIDUAL APPROACHES AND LEVEL OF KNOWLEDGE IN METALLURGY}

As confirmation of the validity of the above-mentioned individual approaches to problem solving, to decisionmaking, respectively for designing we present concrete examples of their application in the conditions of the heat treatment process of raw materials - burning of magnesite in a rotary kiln in order to obtain a refractory material.

\subsection{Case study applications}

The lowest, naive level is the level of elementary decision-making when in a short time it is necessary to take decisions at low cost, most often on the basis of quickly finding a benchmarking or situational primary decision. Note. In such situations, the first wrong decision can later be used as a verified wrong path in the decision tree. The "solve as you know" method is also applicable $[1,2,9]$.

Example of finding a basic, etalon solution (benchmarking): An example of this approach is the solution to the problem of leakage of the twisting rotary kiln contact and the stationary cold (inlet) furnace head through which fake air is sucked into the flue gas exhaust. This causes a number of technological and operational problems. By designing a new type of seal and its successful operational verification, a "standard" of the solution to this problem was obtained, which, after being adapted to the specific technical and spatial conditions, was applied to other furnaces at the customer, respectively with other customers having rotary heat units $[1,2,9]$.

\subsection{Reengineering application}

Heuristic, simulation and analytical models are used to solve partial problems of designing logistics systems, especially decision-making, technological, organizational activities.

Example of using a heuristic approach to a solution: Operator experience is used to solve problems repeatedly, resp. in setting the appropriate operating modes of the rotary kiln for firing a particular type of charge on a particular product. For example, the main quality parameter of a product in the magnesia clinker process is its bulk density. This is determined by the laboratory 2 times for a change of work, since it is not technically possible to ensure continuous operational measurement of this parameter. However, the furnace operator takes a sample of the product at regular 20-minute intervals and visually inspects it after it has cooled. Based on the experience gained from the comprehensive assessment of color, gloss, shape, crystal size and 
rheological properties, the skilled operator can really accurately estimate the bulk density of the sample and then make the necessary corrections in the furnace setting based on this "heuristic".

Simulation models are applied to the design and verification of processes that can be considered as queuing systems $[8,10,11]$. For example, we have a weekly production plan for a production section. However, its realization can be verified in a dynamic form only by a simulation model, the static analytical recalculation of capacities does not take into account the links between individual production operations.

Partial mathematical models are used at the level of exact decision making. These mathematical, but in some situations also physical models arise on the basis of physical-chemical patterns, which in the past were formulated into general mathematical relations and algorithms, whose application requires their adequacy for the specific conditions of the problem solved and the availability of inputs for calculation. An example of solving a particular operational problem based on the partial mathematical model of the hydraulic and thermal conditions prevailing in the rotary kiln head (output) is to determine the repair priority and design a way to remove the glow head seal malfunction. This defect causes false cold air to be drawn into the heat head. To do this, it is necessary to define the real impacts of a given failure on the efficiency of the process.

\subsection{System approach application}

The system approach to designing technology and logistics systems requires systemic problem analysis and synthesis of solutions based on scientific principles. Current rotary kilns have very limited standard options for improving their indicators. This is due to the exhaustion of their optimization potential by several tens of years of improvement, which, with rising energy prices, causes a deterioration in economic efficiency of production. Improving this technological and logistics situation can only be achieved by using complex, innovative solutions that can bring about a significant increase in productivity, efficiency and product quality. Comprehensive, and not partial, innovative measures create new scope for optimization. Their implementation is needed and up to date when the standard optimization potential is already exhausted. Benefits of partial improvement of rotary furnaces by standard technical or as a rule, they do not exceed $1-5 \%$ in operational measures. However, by performing complex optimization, it is possible to achieve higher order benefits, generally above $10 \%$. This value can also be several times higher. It depends on external and internal constraints. External constraints specify the boundaries within which the process can take place. Internal constraints specify the internal process patterns. However, this can only be determined on the basis of complex mathematical models based on the results of a detailed system analysis. The assessment of the impacts and benefits of individual innovation steps through complex mathematical models is a multi-criteria optimization problem and requires the use of correctly selected indicators and criteria (energy, environmental, economic, technological and technical). By way of example, indicators for the magnesite heat treatment process, which are the volume of production per unit of time, the sintering temperature, the energy consumption per ton of product, the thermal gradient of the preheating of the charge to the start of calcination, the quality of the firing product, the total flue gas volume, the amount of drift, etc. [1,2,9,12].

All of these criteria have been used in the comprehensive review of the below developed rotary kiln optimization measures:

- $\quad$ self-regulating continuous batch dispenser,

- $\quad$ radial rolling seal for axial feed furnace,

- $\quad$ sandwich construction of the rotary kiln jacket,

- utilization of the waste heat of the rotary kiln jacket by the controlled cooling system,

- $\quad$ external charge preheater with medium crossover through the charge layer; internal mechanical fluidized bed preheater,

- $\quad$ product cooler with coolant crossover through the charge layer,

- $\quad$ intelligent diffuse burner, etc. 
An example of the visualization of the results of a mathematical model is also an evaluation of the impact of the installation of an external preheater on the process of burning magnesite clinker through the resulting burning curve, which is the result of a complex mathematical model of the process of burning magnesite clinker in a rotary kiln (see Figure 2).

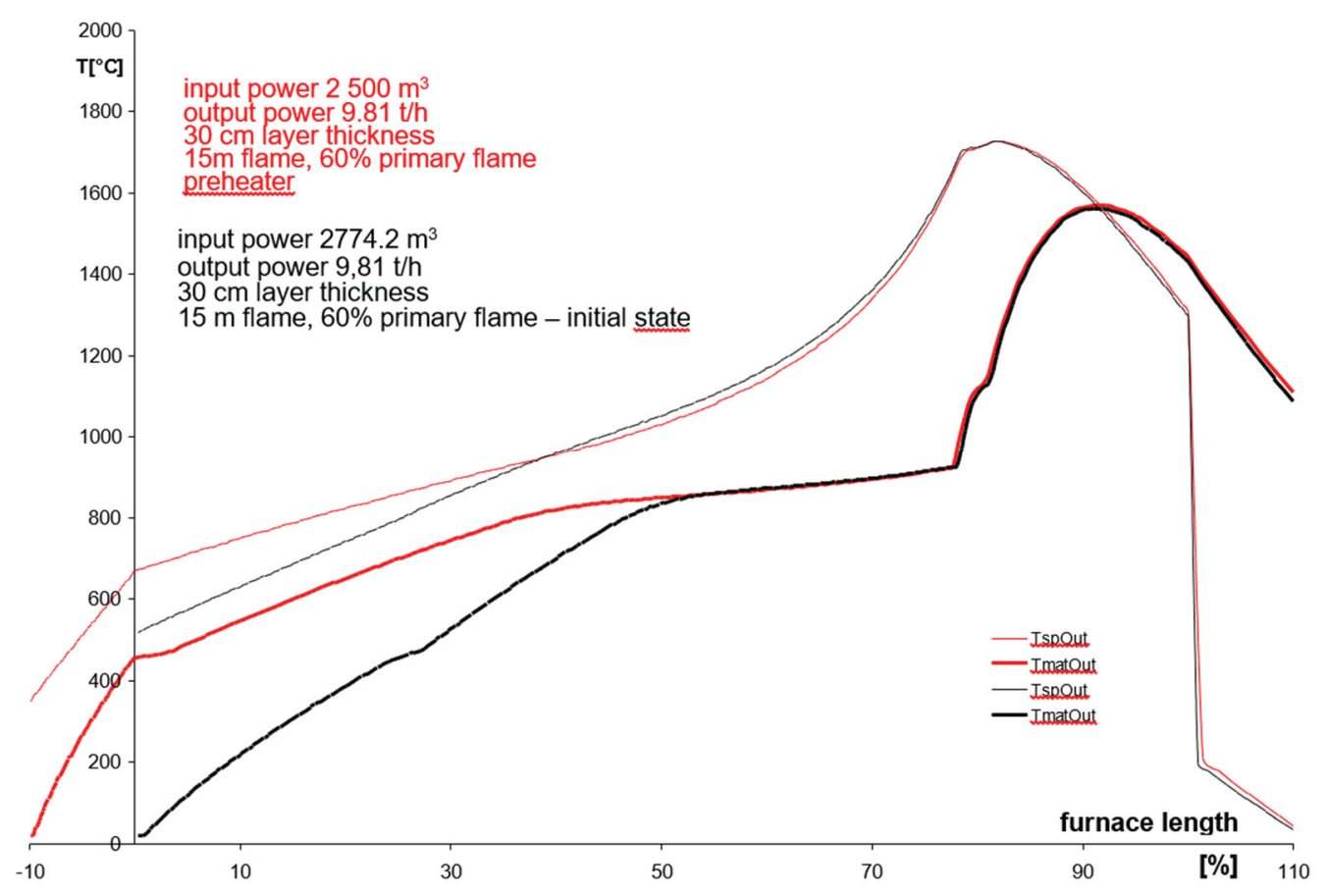

Figure 2 The example of the visualization of the results of a mathematical model

\section{CONCLUSION}

The knowledge used for designing, its scope and depth depends on the extent of the change in the logistics system and the choice of paradigm. The greater the change and the higher the level of paradigm we apply, the wider the range of knowledge and information we apply to design. Logistics system design for a particular business also requires knowledge of technology, economics and management - logistics. That is why it is necessary to know technology, specifics, market positioning in order to logistics system design of the company. It is necessary to "tailor the project". For the successful preparation and implementation of the project it is necessary to know:

- define the problem, the objectives of the project,

- $\quad$ to carry out a quick, "flash analysis" that allows a quick entry into the situation,

- definition of project objectives and design paradigm,

- $\quad$ knowledge of methods of analysis for obtaining information and knowledge.

Knowing the methods of analysis for obtaining information and knowledge is in the form of rules, procedures necessary for the synthesis of logistics systems, e.g. SWOT analysis, statistical analysis for simulation modelling, analysis methodology for simulation modelling, system analysis:

- $\quad$ to know the methodology of decision making of deduction, abduction, induction and analogy,

- $\quad$ to know the methodology of creating simulation and heuristics models,

- to know the operational analysis methods for applying analytical models,

- to know the possibilities of the current information and communication technologies, because most of the logistics system is part of the enterprise information system. 
These are the knowledge that an expert, a logistics specialist designer needs to successfully build logistics systems projects.

\section{ACKNOWLEDGEMENTS}

The submitted work is a part of the project VEGA 1/0317/19 "Research and development of new smart solutions based on principles of the Industry 4.0, logistics, 3D modelling and simulation for production streamline in the mining and building industry." funded by the Scientific Grant Agency of the Ministry of Education, Science, Research and Sport of the Slovak Republic and the Slovak Academy of Sciences.

\section{REFERENCES}

[1] STRAKA, M., LENORT, R., KHOURI, S. and FELIKS, J. Design of Large-Scale Logistics Systems using Computer Simulation Hierarchic Structure. International Journal of Simulation Modelling, 2018. vol. 17, no. 1, pp. 105-118.

[2] MALINDŽÁK, D., KAČMÁRY, P., OSTASZ, G., GAZDA, A., ZATWARNICKA-MADURA, B. and LOREK, M. Design of Logistic System, Theory and Applications. Open Science Publishers, New York, 2015. p. 300.

[3] MALINDŽÁK, D. and BUŠA, M. Levels of knowledge, creativity, heuristics and logistics. Transport and Logistics, 2017. vol. 17, no. 42, pp. 21-26.

[4] GARCIA, T., SPITÉRI, P. and KHENNICHE, G. Behavior of parallel two-stage method for the simulation of steel solidification in continuous casting. Advances in Engineering Software. 2019. vol. 131, pp. 116-142.

[5] AKSYONOV, Konstantin A., ANTONOVA, Anna S., AKSYONOVA, Olga P. and KAI, W. Rules for construction of simulation models for production processes optimization. CEUR Workshop Proceedings. 2018. vol. 2076, pp. 9-18.

[6] REIFFERSCHEID, M. Ideas, techniques and decisions for application of digital technologies in ferrous metallurgy. Chernye Metally. 2018. no. 6, pp. 62-67.

[7] HOLMAN, D., WICHER, P., LENORT, R., DOLEJŠOVÁ, V., STAŠ, D. and GIURGIU, I. Sustainable Logistics Management in the $21^{\text {st }}$ Century Requires Wholeness Systems Thinking. Sustainability. 2018. vol. 10, no. 12, pp. 1-26.

[8] STRAKA, M., TREBUNA, P., ROSOVA, A., MALINDZAKOVA, M. and MAKYSOVA, H. Simulation of the process for production of plastics films as a way to increase the competitiveness of the company. Przemysl chemiczny. 2016. vol. 95, no. 1, pp. 37-41.

[9] KOŠTIAL, I., ORAVCOVÁ, E., GLOČEK, J., SPIŠÁK, J., MIKULOVÁ POLČOVÁ, K., MIKULA, J. Reduction of finegrained waste production in magnesite processing and new technologies for their treatment. Waste Forum. 2012. no. 2, pp. 91-97, ISSN 1804-0195.

[10] VILAMOVÁ, S., BESTA, P., KOZEL, R., PIECHA, M., VANĚK, M., SAMOLEJOVÁ, A., JANOVSKÁ, K. and ČECH, M. Increasing the Efficiency of Production of Iron by Means of Reduction of Harmful Elements. Metalurgija, 2015. vol. 54, no. 4, pp. 649-652.

[11] STRAKA, M., ROSOVA, A., LENORT, R., BESTA, P. and SADEROVA, J. Principles of computer simulation design for the needs of improvement of the raw materials combined transport system. Acta Montanistica Slovaca. 2018. vol. 23, no. 2, pp. 163-174.

[12] SIKOROVÁ, A., LAMPA, M. and SAMOLEJOVÁ, A. Analysis of Maintenance Costs in Metallurgical Enterprise. In METAL 2016: 25th International Conference on Metallurgy and Materials. 2016. Ostrava: Tanger, pp. 2019-2024. 